\title{
Autopsy Findings in a Case of Lepromatous Leprosy Treated with Clofazimine
}

\author{
K. V. DESIKAN, K. RAMANUJAM, G. RAMU AND S. BALAKRISHNAN \\ Central Leprosy Teaching and Research Institute, Chingleput, South India
}

\begin{abstract}
The first recorded autopsy findings are presented on a young person suffering from intractable lepra reaction treated for four months with clofazimine in a dose of $300 \mathrm{mg}$ daily. Apart from a generalized yellow colouration of fatty tissue, brick red in muscle and viscera, extreme congestion and oedema of the mucosa of the small intestine was found, and considered not to be caused by any infectious agent. Deposits of clofazimine crystals were found in the intestinal mucosa.
\end{abstract}

\section{Introduction}

Clofazimine (B 663) is now being extensively used in several leprosy clinics since its efficacy against leprosy as well as against lepra reaction has been well documented. (For review see Aguas, 1971). While its therapeutic action is generally satisfactory, the main side effect is the development of a violaceous colouration due to the accumulation of the rimino-phenazine dye in the skin and mucus membrane. It would be expected that in addition to the deposition in the skin and mucus membrane, the drug accumulates in the internal organs as well. This has been demonstrated in experimental animals (Conalty and Jackson, 1962) but there has been no record of similar changes in the human viscera in patients treated with clofazimine. We recently had an opportunity to examine the changes in various organs during post-mortem examination of a patient who had a course of treatment with B 663 prior to her death. To our knowledge this seems to be the first record of autopsy findings in a patient treated with B 663.

\section{History and Clinical Features}

The patient was a girl aged 12 years when she was first admitted in 1965 to the Central Leprosy Teaching and Research Institute, Chingleput, as a case of lepromatous leprosy. After about five months of treatment with DDS, she absconded from the Institute. Seven years later, she returned with the disease very much advanced and with severe lepra reaction. She was treated initially with antimalarials, and later with antimonial drugs, along with other remedies for relief of her symptoms. During this period, she had mild albuminuria with two to five pus cells per high power microscopic field. After about five months of medication 
with these drugs, the treatment was changed over to prednisolone, $15 \mathrm{mg}$ twice daily. Examination of urine at that time revealed the presence of traces of albumin, pus cells and granular casts. Despite six weeks of treatment with prednisolone, the reaction continued unabated with the development of necrotising skin lesions. The patient was therefore put on $100 \mathrm{mg}$ clofazimine three times a day along with prednisolone. She also received $1 \mathrm{mg}$ DDS twice weekly. During this regimen the patient continued to have bouts of pustulating reaction, though of lesser severity, along with spells of diarrhoea. Examination of stools revealed plenty of pus cells. Clofazimine and prednisolone were continued and the patient also received antibiotics and antidiarrhoeal drugs. She continued to have a moderate albuminuria with pus cells and granular casts. Creatinine clearance was $69 \mathrm{ml} / \mathrm{min}$, blood urea was $17 \mathrm{mg} / 100 \mathrm{ml}$. There was a marked reduction of plasma proteins. After about a month of treatment with clofazimine and prednisolone, she showed a significant improvement in her reactive state. In less than a week however, severe pustular reaction and lymphadenitis set in. She continued to receive clofazimine. The dose of prednisolone was increased to $40 \mathrm{mg}$ a day along with antibiotics. She developed oedema of the face, chest wall and extremities although her urinary output was not seriously affected. The creatinine clearance was $57 \mathrm{ml} / \mathrm{min}$. She continued to have bouts of diarrhoea necessitating reduction in the dosage of clofazimine and finally its total withdrawal. She had received clofazimine for a total period of nearly 4 months at $300 \mathrm{mg}$ a day. One month later she died. The cause of her death was considered to be nephrotic syndrome, presumably precipitated by recurrent lepra reaction. Details of biochemical investigations carried out on a number of occasions are presented in the following table.

TABLE 1

Biochemical findings

\begin{tabular}{|c|c|c|c|c|c|c|}
\hline & $27-7-72$ & $24-8-72$ & $22-9-72$ & $18-10-72$ & $4-11-72$ & $22-22-72$ \\
\hline $\begin{array}{l}\text { Blood urea } \\
\quad(\mathrm{mg} / 100 \mathrm{ml})\end{array}$ & 17 & 18 & 20 & 24 & 20 & 24 \\
\hline $\begin{array}{l}\text { Serum protein } \\
\text { Total } \mathrm{g} / 100 \mathrm{ml} \\
\text { Albumin } \mathrm{g} / 100 \mathrm{ml} \\
\text { Globulin } \mathrm{g} / 100 \mathrm{ml}\end{array}$ & & $\begin{array}{l}3.2 \\
1.5 \\
1.7\end{array}$ & $\begin{array}{l}3.5 \\
1.8 \\
1.7\end{array}$ & $\begin{array}{l}3.5 \\
1.8 \\
1.7\end{array}$ & $\begin{array}{l}3.5 \\
1.6 \\
1.9\end{array}$ & $\begin{array}{l}3.2 \\
1.5 \\
1.7\end{array}$ \\
\hline $\begin{array}{l}\text { Serum cholesterol } \\
\qquad(\mathrm{mg} / 100 \mathrm{ml})\end{array}$ & & 136 & 200 & 155 & 168 & 125 \\
\hline $\begin{array}{l}\text { Creatinine } \\
\quad \text { Clearance } \mathrm{ml} / \mathrm{min}\end{array}$ & 69 & 57 & & & & \\
\hline $\begin{array}{l}\text { Serum sodium } \\
\quad(\mathrm{mEq} / \mathrm{l})\end{array}$ & & & & 136 & 134 & 130 \\
\hline $\begin{array}{l}\text { Serum potassium } \\
\qquad(\mathrm{mEq} / \mathrm{l})\end{array}$ & & & & 4.0 & 4.3 & 3.0 \\
\hline
\end{tabular}

\section{Salient Post-Mortem Findings}

The body was that of a moderately built adult female patient of lepromatous leprosy with extensive scars of healed ulcers all over the body. There was postmortem lividity camouflaging the colouration due to clofazimine. The 
abdomen was distended and contained 31 of clear watery fluid. The most striking finding on opening the abdomen and chest was the bright orange-yellow colouration of the fat and brick-red colouration of the muscles (Fig. 1). This colouration, particularly of the fat, was extensive throughout the body in all locations. The loops of intestine and the omentum were also found to be bright orange-yellow in colour, when the abdomen was opened. However, the colour faded on exposure to light for some time. The serosal surface of the intestine was smooth and there were no adhesions between the loops of intestine. On opening the small intestine, the mucosa was seen to be intensely red, extremely oedematous and markedly boggy (Fig. 2). A careful examination of the entire
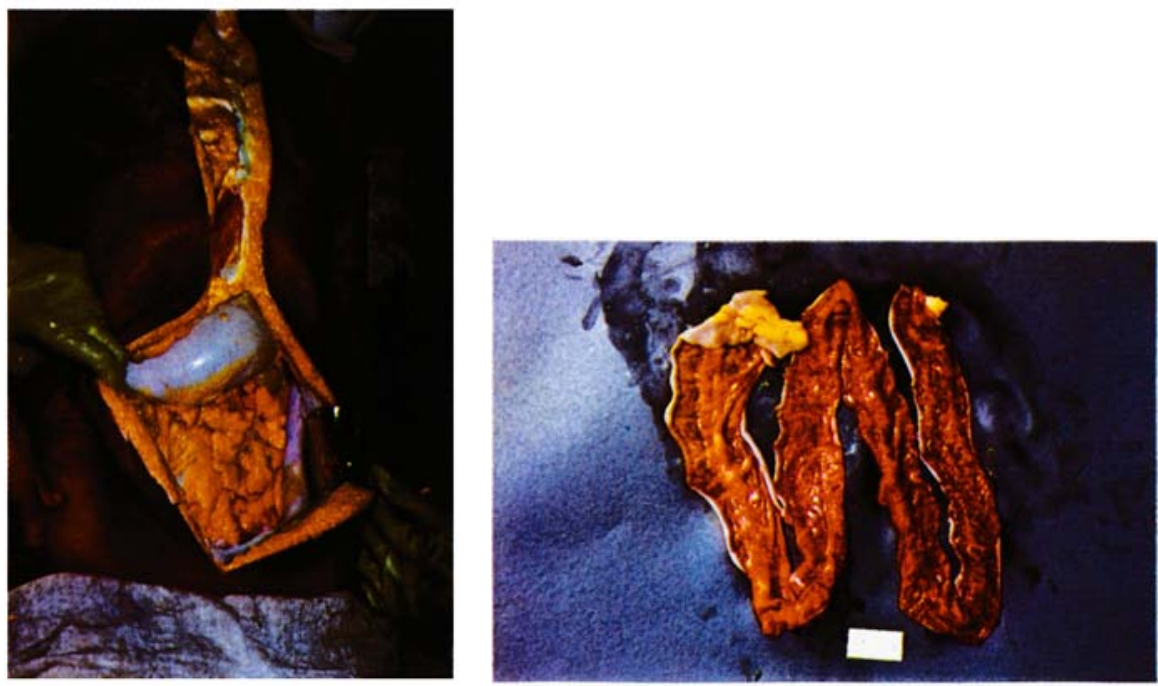

Fig. 1. Autopsy finding in the case treated with clofazimine. Note the bright orange-yellow colouration of the fat and brick-red colouration of the muscle.

Fig. 2. Mucosal surface of the small intestine showing the intense red colouration and oedema.
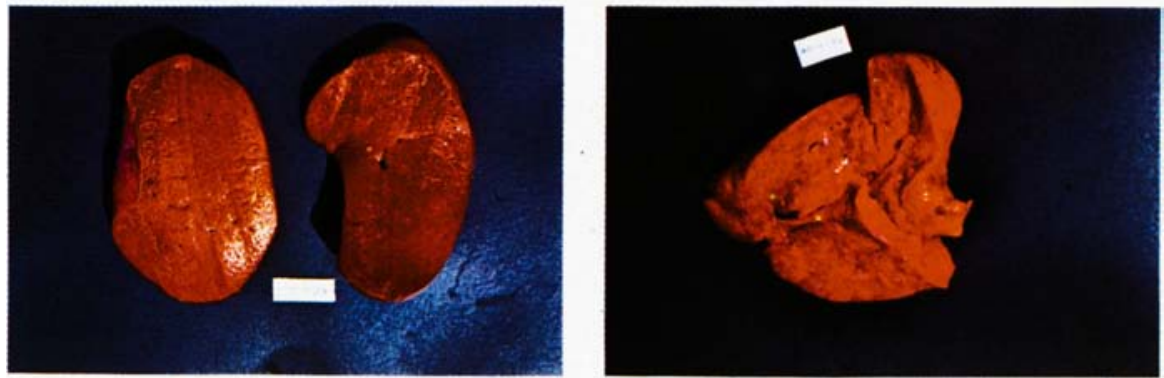

Fig. 3. Cut surface of the spleen. The bright brick-red colouration is quite distinct from the colour due to congestion of the pulp.

Fig. 4. Cut surface of the lung. Notice the bright brick-red colouration of the parenchyma. 
length of the small intestine did not show any ulceration or necrosis. The large intestine was similar in appearance although not so severely inflamed.

The pleural cavities contained about $500 \mathrm{ml}$ of clear watery fluid on each side. The right and left lung weighed 340 and $300 \mathrm{~g}$ respectively. The outer surface was smooth and bright red in colour. The cut surface showed bright brick-red colouration, which was quite distinct from the usual colouration due to congestion (Fig. 4). Both the lungs were well aerated. The larynx, treachea and bronchi showed no lesion.

The liver weighed $1500 \mathrm{~g}$. The outer surface was reddish-brown in colour. The edges were rounded. The cut surface was congested and slightly greasy. The gall bladder and bile ducts showed no lesion. The pancreas was normal.

The spleen weighed $450 \mathrm{~g}$. It was very firm and rubbery in consistency. The cut surface showed a prominent pulp which was bright brick red in colour (Fig. 3). The superficial lymph nodes were enlarged. The lymph nodes showed no significant lesion.

The kidneys were large, the right and the left weighing 140 and $160 \mathrm{~g}$ respectively. The outer surface was smooth. The capsule stripped easily. The cut surface showed the pelvic pad of fat coloured orange-yellow. The cortex and medulla were well demarcated. No significant lesion was seen. The ureters and bladder were normal.

The cardiovascular system and genital system showed no lesions. The brain and spinal cord were not examined. Of the endocrine glands, the thyroid, parathyroids and adrenals were examined. No macroscopic lesion was found.

\section{Microscopic Findings}

The most striking finding on gross examination was the extreme congestion and oedema of the mucosa of the small intestine. On histological examination the mucosa and submucosa were found to be infiltrated by polymorphs and lymphocytes. There was marked oedema with several dilated and congested blood vessels. There was no evidence of ulceration, necrosis or haemorrhage. A mild inflammatory cell exudate was also found in the muscular and serosal coats in areas. The large intestine also showed oedema and congestion of the mucosa with a moderate infiltration by polymorphs and lymphocytes. A search was made for clofazimine crystals. In the routine paraffin sections, these crystals were not found, apparently because during the process of preparing the tissue for paraffin sections and during staining, the crystals may have dissolved, leaving "ghosts" of the crystalline material. Such "ghosts" were found in the haematoxyline eosin sections, but their identity was doubtful. Frozen sections were therefore cut, mounted and examined, unstained. Careful search of these sections showed small collections of yellowish-black material in the intestinal mucosa. The location of these deposits and the shape of the crystals within the clumps are strongly in favour of the material being clofazimine crystals. The change in the colour of the crystals was thought to be due to the fixation of the tissues in formalin. Examination of fresh tissue material for clofazimine crystals was not carried out at the time of autopsy, and all the organs were preserved in formalin. Frozen sections of the formalin-fixed tissues were cut several days later, and this may have been the reason for the blackish colouration of the crystals in the sections. Apart from the intestine, the liver, spleen and lung also showed the crystals (Figs 5 and 6). 


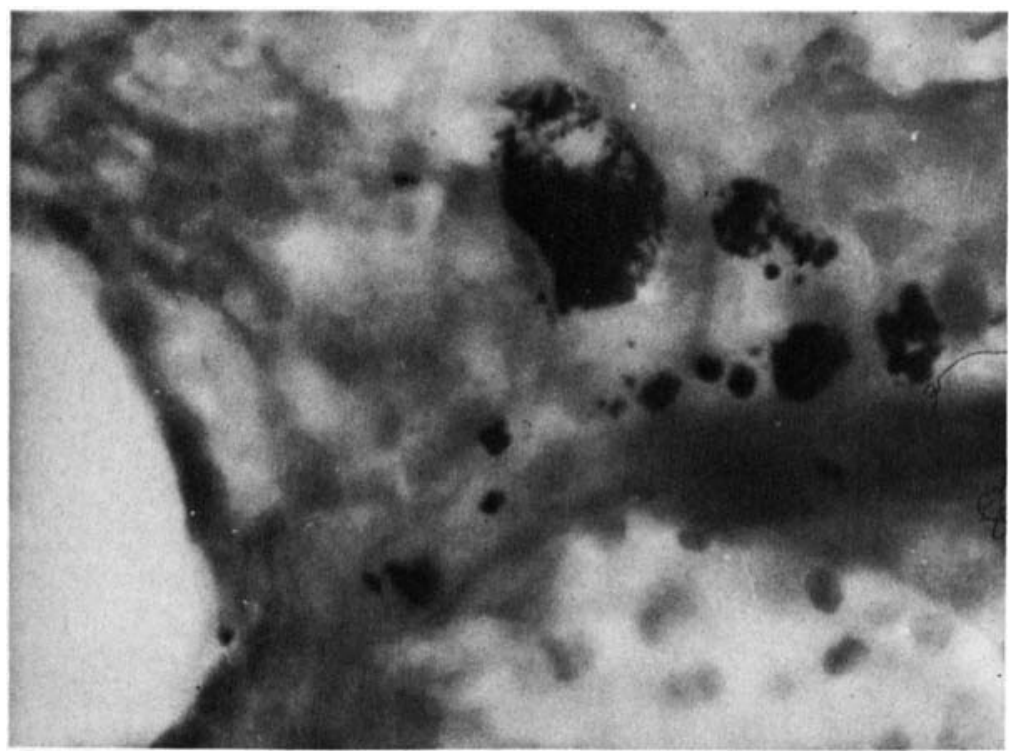

Fig. 5. Photomicrograph of the liver showing clof azimine crystals in a macrophage. (x 500.)

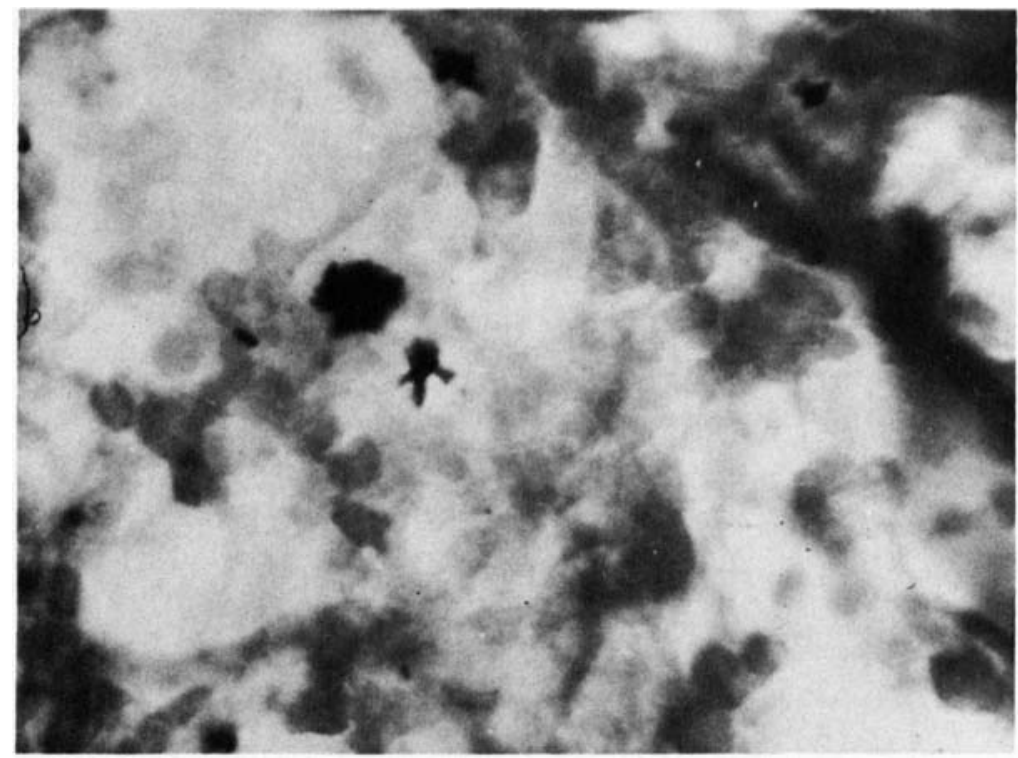

Fig. 6. Section of lung showing collection of the crystals in a macrophage. ( $\times 500$.) 
Lepromatous granulomata, a millimeter or less in diameter, composed of collections of foamy macrophages with a few lymphocytes, were seen in the liver, occupying different parts of the lobule. Fragmented acid-fast bacilli in small groups were found in the macrophages. The bacilli were also found in small numbers in the Kupffer cells, and very occasionally in the liver cells. Miliary lepromatous granulomata containing acid-fast bacilli similar to those described above were also found in the spleen and in the adrenals. Lymph nodes showed partial replacement by lepromatous granuloma, mainly in the paracortical areas, and acid-fast bacilli were found in moderate number in the macrophage cells composing the granuloma. The larynx showed a lepromatous granuloma mainly in the vocal cords and epiglottis, with numerous acid-fast bacilli. The bacilli were also found in the bone marrow, kidney and lung, located mainly in endothelial cells of the blood vessels or in stray macrophages.

There was a massive amyloid deposit in the spleen. Most of the red pulp of the spleen was replaced by amyloid. The white pulp was seen as small islands of cells amidst the amyloid. A heavy amyloid deposit was also found in the kidney (Fig. 7). Most of the glomeruli were completely or partially replaced by the amyloid. The adrenal cortex was seen as a mass of amyloid material (Fig. 8). Small areas of zona glomerulosa were found intact, but the rest of the adrenal cortex was replaced by amyloid material. Amyloid deposit in the liver was very little. The blood vessels in practically all the organs showed amyloid change in. varying degrees, marked particularly in the uterus and ovary. The organs examined showed no singificant lesion apart from the amyloid deposit in the blood vessel walls.

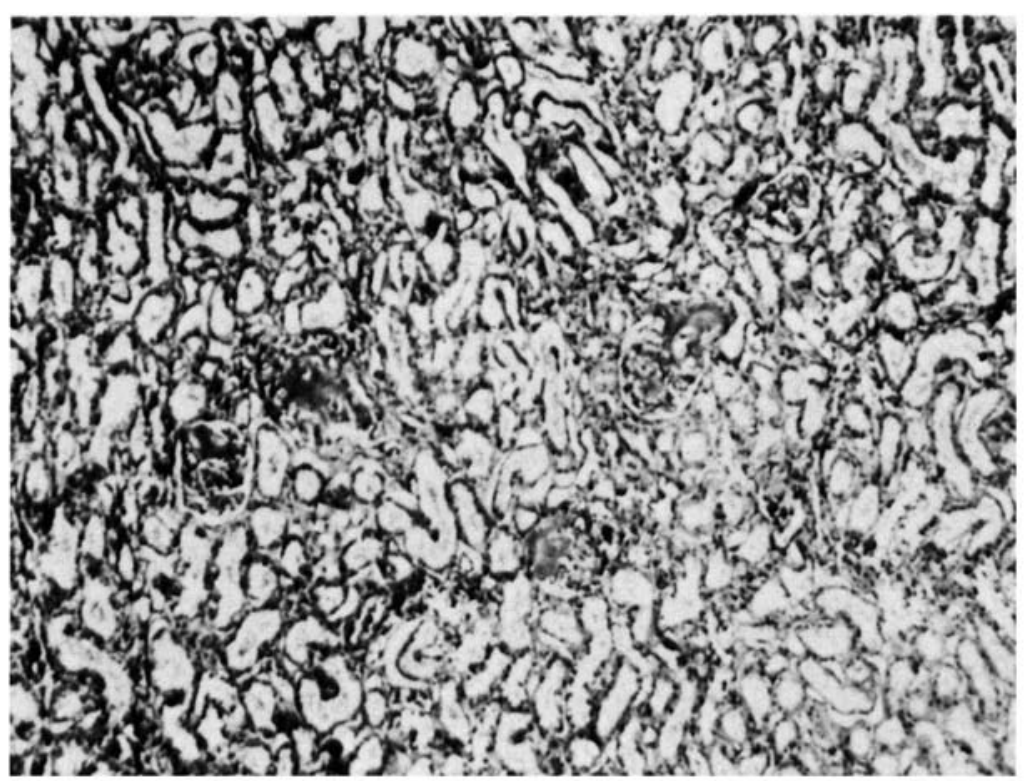

Fig. 7. Section of kidney showing amyloid deposit in the glomeruli. ( H \& E x120.) 
In summary, this 22 year old woman was a patient of lepromatous leprosy with repeated reactions. Having been treated with clofazimine, there was a striking colour change in the skin and internal organs. The subcutaneous fat, as well as fat in other locations were stained bright orange-yellow. Muscles, liver, spleen, kidneys and lungs showed bright brick-red colouration. The entire length of the intestines showed profuse oedema and severe congestion of the mucosa. Absence of ulcerations or necrosis indicated that this severe enteritis was not due to any infectious agent. Unstained frozen sections showed several small clumps of clofazimine deposited in the intestinal mucosa, lungs, liver and spleen. There was in addition a severe secondary amyloidosis, with massive deposit of amyloid in spleen, kidney and adrenal cortex and also an amyloid change in the blood vessels of organs. Lepromatous granulomata were seen in liver, spleen, lymph nodes, adrenal cortex and larynx. Acid-fast bacilli were seen in the granulomata as well as in the endothelial cells of blood vessels in other organs.

Renal amyloidosis was the cause of nephrotic syndrome in this patient. Some of the sequential biochemical observations carried out on various occasions showed a persistently low level of plasma proteins. There was albuminuria and a mild increase in the serum cholesterol level on one or two occasions. These features are consistent with nephrotic syndrome complicating lepromatous leprosy as has been reported earlier (Ramanujam et al., 1973). However, she did not develop uraemia, but the sudden downhill turn of her condition and ultimate death could be explained by adrenal failure due to rapid amyloid deposit in the adrenal cortex.

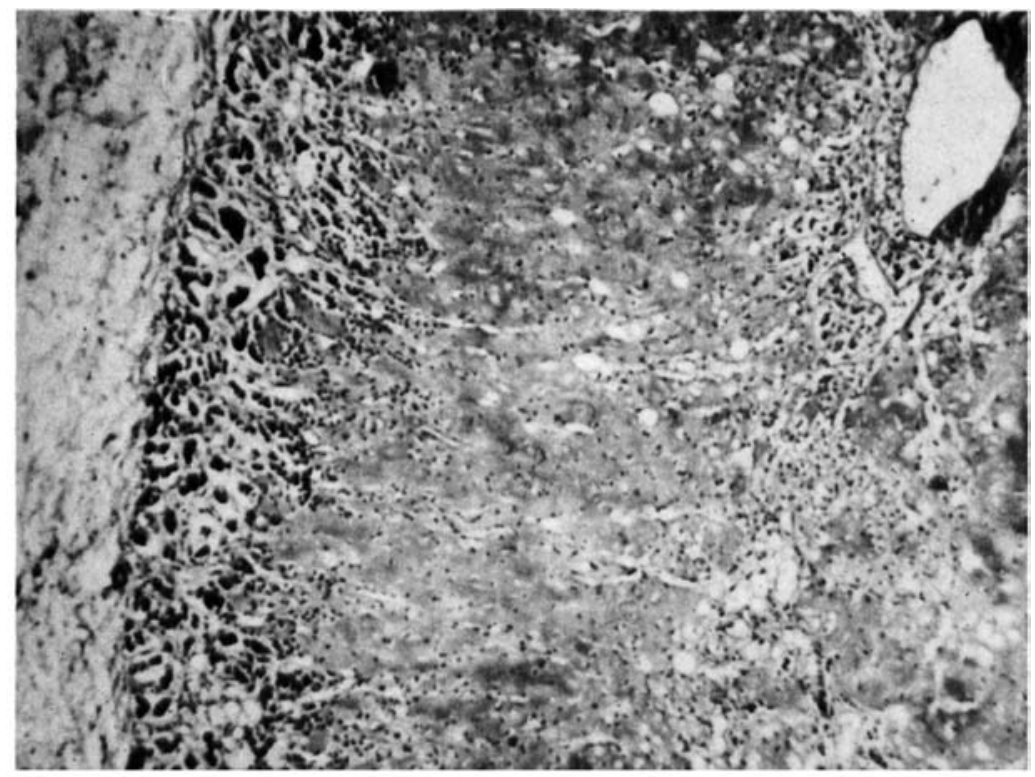

Fig. 8. Section of adrenal cortex with almost total replacement by amyloid. (H \& E x 120.) 


\section{Discussion}

This case is being presented primarily to high-light the colour changes in the internal organs subsequent to clofazimine therapy. Although acclaimed to be a very efficacious drug against leprosy and lepra reactions, its chief disadvan tage is the colouration of the skin, particularly in light coloured patients. Since the active ingredient of the drug is a dye which has a tendency to get accumulated in the RE cells (Conalty et al., 1971) such a colouration of the organs is expected. Mice fed in this laboratory with diet containing $0.1 \%$ clofazimine showed colouration of the skin in the first week. After 4-6 weeks, it was found that the animals had lost considerable amount of weight. The subcutaneous fat showed bright yellowish orange colour. The liver, spleen and lymph nodes were reddish brown and the intestines were purplish black. These changes in animals have been described by other workers (Conalty and Jackson, 1962) but visceral changes in leprosy patients due to clofazimine therapy have not been reported. In the case presented, the colouration was most obvious in the adipose tissue in all locations. The subcutaneous fat, the fat in the omentum and mesentery was strikingly bright orange-yellow in colour. Such a colour change has also been observed in the subcutaneous fat while performing skin biopsies of several other patients on clofazimine therapy. Of the other internal organs the most striking colour change was found in the lungs and spleen.

One of the complicating conditions of the patient was the recurrent diarrhoea. A very careful examination of the intestine did not reveal any ulceration or necrosis. An infectious aetiology was therefore ruled out. The enteritis was in all likelihood due to clofazimine. Deposits of clofazimine crystals were found in the intestinal mucosa. It must be mentioned however that the reddish colouration of the mucosa was out of proportion to the comparatively moderate inflammation of the small intestine. This is obviously due to the staining by clofazimine which gave the startling impression of severe enteritis on gross examination. The diarrhoea in this patient was not severe and certainly did not contribute to her death, but it necessitated a reduction in the dose of the drug and its final withdrawal.

There have been several references in the literature to enteritis as a side effect of clofazimine therapy. Williams et al. (1965) described gastrointestinal disturbances in all the cases treated by them. One of the patients had abdominal cramps and severe diarrhoea necessitating frequent stoppage of the drug. These patients were receiving $600 \mathrm{mg}$ of clofazimine daily. On a similar dose Atkinson et al. (1967) found that one of the patients had anorexia, epigastric distress, vomiting and abdominal pain with rebound tenderness. X-ray examination showed evidence of small bowel irritation. Peroral jejunal biopsy showed normal mucosal villous pattern with moderate number of plasma cells in the lamina propria. Devadasan (1970) has described abdominal discomfort in one patient out of eight treated. In three patients treated by Schulz (1972) with a maximal dose of 300 to $400 \mathrm{mg}$ of clofazimine, there was constipation or diarrhoea severe enough to stop treatment. All routine examinations including roentgenography did not show any intestinal lesions. Two of these patients tolerated the drug in smaller doses. Ten other patients complained of transient abdominal pain and nausea, but the treatment with clofazimine was uninterrupted. Two out of 15 patients treated by Helmy et al. (1972) and one out of 20 patients treated by Pene et al. (1971) had abdominal discomfort, vomiting or diarrhoea, but treatment was uninterrupted. 
Gastrointestinal disorders have also been mentioned by Aguas (1971) and Theophilus (1972).

Our own experience has been that gastrointestinal symptoms, especially diarrhoea, were a frequent side effect of clofazimine therapy, sometimes necessitating reduction of dose or temporary suspension of the drug. In the case presented, diarrhoea was frequent and severe. Consequently, the dose of the drug was reduced and finally stopped. It is interesting to note that although the patient did not have the drug for nearly a month before her death, and was practically free of diarrhoea, the morphological findings in the intestine were very severe, far more than was clinically obvious.

\section{Acknowledgement}

The authors acknowledge with thanks the help provided by $\mathrm{Mr}$ C. Samuel in preparing the photographs, Mr P. B. Nath in making the histological sections and Mr M. Nagarethinam in the secretarial work. Financial assistance provided by messrs Geigy Ltd, Basel and LEPRA for publishing the colour illustrations is gratefully acknowledged.

\section{References}

Aguas, J. T. (1971). Treatment of leprosy with Lampren (B 663 Geigy). Int. J. Lepr. 39, 493.

Atkinson, A. J., Sheagren, J. N., Rubio, J. B. and Knight, V. (1967). Evaluation of B 663 in human leprosy. Int.J. Lepr. 35, 119.

Conalty, M. L., Barry, V. C. and Jina, A. (1971). The antileprosy agent B 663 (Clofazamine) and the reticulo-endothelial system. Int. J. Lepr. 39, 479.

Conalty, M. L. and Jackson, R. D. (1962). Uptake by reticulo-endothelial cells of the Riminophenazine B 663 (2-p-chloroaniline-5-p-chlorophenyle 3:5 dihydro-3isopropyliminophenazine) Br. J. exp. Path. 43, 650 .

Devadasan, C. (1970). B 663 (Geigy 30-320) in the treatment of leprosy. A preliminary report. Acta. Trop. 26, 265. (Abstract in Trop. Dis. Bull. 67, 420.)

Helmy, H. S., Pearson, J. M. H. and Waters, M. F. R. (1972). Treatment of moderately severe ery the ma nodosum leprosum with clofazamine. A controlled trial. Lepr. Rev. 42, 167.

Pene, P., Carrie, J., Bourgeade, A. and Bolliot, Y. (1971). Activitees der B 663 dans la lepre lepromateuse essai therapeutique. Bull. Soc. Path. exot. 64, 407. (Abstract in Trop. Dis. Bull. 69, 635.)

Ramanujam, K., Ramu, G., Balakrishnan, S. and Desikan, K. V. (1973). Nephrotic Syndrome complicating lepromatous leprosy. Indian J. med. Res. 61, 548.

Schulz, E. J. (1972). Forty-four months' experience in the treatment of leprosy with clofa zi mine (Lampren Geigy) Lepr. Rev. 42, 178.

Theophilus, S. (1972). Report of treatment with B 663. Lep. Ind. 44, 103.

Williams, T. W., Mott, P. D., Westlake, P. T., Barba Rubio, J., Alder, R. C., Hill, G. J., Perez Suarez, G. and Knit, V. (1965). Leprosy research. in National Institutes of Health: Experience with B 663 in the treatment of leprosy. Int. J. Lep. 33, 767. 